\title{
Practices and Determinants of Exclusive Breastfeeding among Young Mothers Attending a Secondary Health Care Facility - A Cross Sectional Study
}

\author{
By Hemant Kumar ${ }^{*}$ \& Ruchita Satish Gaonkar ${ }^{ \pm}$
}

\begin{abstract}
The benefits of exclusive breastfeeding $(E B F)$ cannot be over emphasized, especially in a country like India, where nearly 600,000 newborns die within 28 days of their birth every year while only $54.9 \%$ infants are exclusively breast fed. Lives of 820,000 children under-five, could be saved if all children aged 0-23 months were optimally breastfed. Present study tried to assess the prevalence of EBF among study subjects and its socio-demographic determinants, in rural South India. This was a cross-sectional study that employed a structured questionnaire to collect data from 182 mothers, attending a rural hospital in South India, from April 2019 to September 2019 selected through convenience sampling. The study reveals that less than half of the respondent mothers (48.3\%) practiced exclusive breastfeeding. Four socio-demographic factors were found to be significantly associated with EBF practices and these were - age of mother $(p=0.004753)$, gender of the infant $(P<0.000634)$, number of antenatal visits $(p>0.01148)$ by respondents and caesarean Section delivery $(P<0.027847)$. In our study, EBF practices were found to be suboptimal giving rise to a need to educate every pregnant or lactating mother during their antenatal or post-natal visits by our health care workers about EBF and its benefits.
\end{abstract}

Keywords: Exclusive breastfeeding, Complementary food, Infant feeding, Determinants, Barriers

\section{Introduction}

Breastfeeding is one of the most effective ways to ensure child health and survival (WHO 2017a). Colostrum, the yellowish, sticky breast milk produced at the end of pregnancy, is recommended by the World Health Organization (WHO) as the perfect food for the newborn, and feeding should be initiated within the first hour after birth (WHO 2020a). Breastfeeding is potentially one of the top nutrition interventions for reducing under-five mortality. Over 820,000 children's lives could be saved every year, if all children 0-23 months were optimally breastfed. Improving child development and reducing health costs through breastfeeding results in economic gains for individual families as well as at the national level (WHO and UNICEF 2003). Further, increased breastfeeding is associated with US $\$ 302$ billion annually in additional income - nearly 0.5 per cent of world gross national income (WHO 2017b, c). World Health Assembly had set a target of increasing the rate of exclusive breastfeeding in the first 6 months up to

\footnotetext{
* Professor \& Head, Department of Community Medicine, A.J. Institute of Medical Sciences \& Research Center, India.

${ }^{ \pm}$Clinical Tutor, Department of Community Medicine, A.J. Institute of Medical Sciences \& Research Center, India.
} 
at least 50 per cent compared to the prevalent rate of 40 per cent by 2025 globally (WHO 2020b).

While breastfeeding rates have improved globally, disparities in breastfeeding practices persist particularly in rural and low resource settings. In low and middle income countries (LMICs), only $37 \%$ of children are breastfed exclusively for the first 6 months of life (Victora et al. 2016). Situation in India is no better, as National Family Health Survey-2015-16 (NFHS-4), brings out that only 42.6\% mothers initiated breastfeeding within one hour of birth, while only $54.9 \%$ children were exclusively breastfed ( $u$ rban $=52.1 \%$, rural $=56 \%$ ). While majority of the states have registered improvement in EBF practices, the trends in Kerala and Karnataka have shown a decline i.e., from $56.2 \%$ to $53.3 \%$ and from $58.6 \%$ to $54.2 \%$ respectively (MHFW 2017, POSHAN 2017).

As India leads the world in the number of preterm births and neonatal mortality, understanding the factors associated with EBF can help in improving the nutritional status of millions of infants, and reducing neonatal mortality rate (UNICEF 2019a). Keeping in view the declining trends of EBF in Karnataka, present study was conceived and conducted among rural mothers attending a subdistrict (SDH) Hospital located in Bantwal, Dakshina Kannada District, Karnataka, India, with an aim to determine prevalence of EBF and the socio-demographic variables which may have an association with it, as these findings may be useful later on, in planning and implementation of EBF intervention programs in the community.

\section{Literature Review}

Breastfeeding, also called nursing, is the process of feeding mother's breast milk to her infant, either directly from the breast or by expressing (pumping out) the milk from the breast and bottle-feeding it. Breast milk provides the infant with essential calories, vitamins, minerals, and other nutrients for optimal growth, health, and development. Breastfeeding is beneficial to both, the mother and her infant, and also offers an important opportunity for the pair to bond (NIH 2017).

WHO, as well as UNICEF recommend initiation of breastfeeding within the first hour after the birth; exclusive breastfeeding for the first six months; and continued breastfeeding for two years or more, together with safe, nutritionally adequate, age appropriate, responsive complementary feeding starting in the sixth month. Similar recommendations have also been made by American Academy of Paediatrics on breastfeeding (UNICEF 2015, NIH 2017).

Studies reveal that newborns that started breastfeeding between two and 23 hours after birth had a $33 \%$ greater risk of dying as compared to those who began breastfeeding within one hour of birth. Among newborns that started breastfeeding a day or more after birth, the risk was more than twice as high. Further, an exclusively breastfed child is 14 times less likely to die in the first six months of life than a non-breastfed child, as breastfeeding drastically reduces deaths from acute respiratory infection and diarrhea, the two major child killers (WHO 2018). Sadly, only $44 \%$ of new-born are put to the breast within the first hour of birth 
globally and only 2 in 5 infants less than 6 months of age are exclusively breastfed (UNICEF 2019b). WHO (2012) recommends that a new mother should have at least 16 weeks of absence from work after delivery, to be able to rest and breastfeed her child (WHO 2012).

Studies also bring out that exclusive breastfeeding helps children support healthy brain development, improves cognitive performance and is associated with better educational achievement at the age of five years (UNICEF 2015). Research further indicates that, breastfeeding supports infants' immune system and may also protect them later in life from chronic conditions such as obesity and diabetes (WikiLectures 2014). Besides, breastfeeding also benefits the mothers in many ways - it lowers their risks of breast and ovarian cancer, helps them return to their pre-pregnancy weight faster, reduces the rates of obesity and lowers the incidence of postpartum depression (WHO 2013, Hamdan and Tamim 2012).

Questions have been asked as to why not to use infant formula? The answer is that infant formula does not contain the antibodies found in breast milk and is also linked to some inherent risks, such as water-borne diseases that arise from mixing powdered formula with water which may not be safe sometimes, over-diluting formula to "stretch" supplies and the cost of formula may not be affordable to many poor families. Infants who receive formula feedings are also at a higher risk for acute otitis media, asthma, diabetes, eczema, lower respiratory tract and infections. Besides, formula is harder to digest for a new born baby and stays in the stomach longer than breast milk, which may cause the baby to feed less often and cause a decrease in milk production of the mother (Dartmouth-Hitchcock 2020).

Studies in India and abroad bring out that EBF practices are sub-optimal in most of the developing countries while India is no exception. Research indicates that the main modifying variables to EBF practices are-the age of the mother, her educational status, economic status of the family, occupation/employment of the mother, parity, antenatal care, multiple births, cue to action/self-efficacy, type of delivery, birth weight of infant, previous experiences with breastfeeding, support from family and friends, support from health workers, knowledge of feeding babies, maternal prenatal intention, lack of awareness about benefits of EBF, personal motivation and perception of having insufficient milk secretion (Andy 2015).

Some of the studies undertaken in India and abroad on EBF and the various factors which influence it are given below:

Tarrant et al. (2010) conducted a prospective study on antenatal women who delivered healthy, term singleton infants, at 6 weeks and 6 months postpartum. Results brought out that breastfeeding initiation rates of the Irish-national and nonIrish-nationals were $47 \%$ and $79.6 \%$, respectively, while the factors which were significantly associated with both breastfeeding initiation and 'any' breastfeeding at 6 weeks included age of the mothers ( $>35$ years) and educational status. The negative perception that breastfeeding is an embarrassing way to feed an infant was demonstrated as a major barrier to initiation. The author recommended that health campaigns that focus on increasing the social acceptability of breastfeeding may prove effective in addressing this cultural barrier (Tarrant et al. 2010). 
Bakoula et al. (2007) conducted a longitudinal study among 3734 Greek mothers to determine the prevalence and socio-demographic, psychosocial and environmental factors associated with maternal infants feeding intention. The results showed that any breastfeeding at 3 to 6 months were 52\% and $24 \%$ respectively. The corresponding rates of exclusive breastfeeding were $37 \%$ and 17\%. The author recommended health education programmes to support breastfeeding were necessary with special focus on non-working mothers and mothers who did not have previous breastfeeding experience (Bakoula et al. 2007).

Edmond et al. (2006) in his study among 10947 breastfed babies brought out that breastfeeding was initiated within the first day of birth in $71 \%$ of infants and by the end of day 3 in all but $1.3 \%$ of them, while $70 \%$ were exclusively breastfed during the neonatal period. Delay in the time of repair of episiotomy and labor duration less than 12 hours were associated with early breastfeeding initiation. Early contact between baby and mother, help received on the delivery table and the presence of more than one delivery assistant, positively influenced breastfeeding initiation (Edmond et al. 2006).

Behzadifar et al. (2018) in a systematic review and meta-analysis in Iran brought out an overall prevalence of EBF to be 53\%. The OR for breastfeeding education received before pregnancy was 1.13 , for mother's job -1.01 , for education level -1.12 , for type of delivery -1.16 and for gender of child -1.03 (Behzadifar et al. 2018).

Oakley et al. (2013) in their study in England (2010-2011), which included all the 151 primary care trusts (PCTs) in England, observed considerable variations in breastfeeding with breastfeeding initiation mean $-72 \%$, any breastfeeding at 6-8 weeks mean $-45 \%$, and exclusive breastfeeding at 6-8 weeks mean -32\%. Maternal age was strongly associated with breastfeeding. Weaker associations were observed between socio-demographic factors and breastfeeding in London PCTs (Oakley et al. 2013).

Raveendran et al. (2020) in their study in Kerala (India) brought out rather low prevalence of EBF i.e., $21.9 \%$, with a median duration of four months. Main factors which influenced the EBF were observed to be maternal education, occupation of mother and advice on exclusive breastfeeding during antenatal visits. Perception of inadequacy of breast milk was found to be the major barrier to non-exclusive breastfeeding (Raveendran et al. 2020).

According to Hayden et al. (2009) health behavior is determined by personal beliefs and perceptions which are based on four constructs -perceived susceptibility, perceived severity or seriousness, perceived barriers and perceived benefits. The individual perception together with cues to action and self-efficacy determine the health behavior or action. Studies bring out that the success of a breastfeeding promotion program will depends on understanding the major constructs which are modified by variables such as culture, educational level, past experiences, skill, socio-demographic variables and motivation (Hayden et al. 2009).

The review of literature thus brings out a huge scope for improvement of EBF practices globally as well as in our country, and also the need to understand 
various socio-demographic characteristic like age, education, parity, economic status, and employment which may influence the these practices.

\section{Methodology}

Study Design: Present study was a cross-sectional descriptive study, conducted over a period of two months from 1 August 2019 to 30 September 2019; in a subdistrict (SDH) Hospital located in Bantwal, Dakshina Kannada District, Karnataka, India. The reason for selecting the ibid hospital was that our Medical College has memorandum of understanding $(\mathrm{MoU})$ for training and research of our undergradduate and post-graduate students.

Study Population: The study included all lactating mothers, attending the ibid hospital outdoor patient department (OPD) and had at least one living child aged less than two year and were willing to participate in the study. Convenience sampling method was adopted keeping in view the time frame and the available resources. Finally a total of 182 mothers were enrolled in the study.

The Study Instrument and Data collection: A structured questionnaire was then administered to the study respondents through face to face interviews after taking written informed consent from the participants. Approval of Institutional Ethical Committee (IEC) was obtained before the conduct of study. The participants were asked questions related to current breastfeeding practices and recall as to how early they initiated breastfeeding after the delivery including questions on complementary feeding, bottle feeding, any other foods or liquids given to the infant during first six months. The questionnaire also collected information on socio-demographic characteristics of the mothers, type and place of delivery, and their knowledge about EBF.

Statistical Analysis: Data entry was done using Microsoft excel 2010 and analyzed using SPSS version 20.0. The descriptive parameters have been represented as frequencies and percentages. The chi-square test has been used for assessing the significance of breastfeeding practices and selected variables. The $\mathrm{p}$ value less than 0.05 have been taken as significant.

\section{Operational Definitions}

Breastfeeding practices were assessed based on the World Health Organization (2008) definitions for assessing infant and young child feeding practices (WHO 2008).

Exclusive breastfeeding: Exclusive breastfeeding" is defined as no other food or drink, not even water, except breast milk (including milk expressed or from a wet nurse) for 6 months of life, but allows the infant to receive ORS, drops and syrups (vitamins, minerals and medicines). 
Early initiation of breastfeeding: Proportion of children born in the last 24 months who were put to the breast within one hour of birth.

Exclusive Breastfeeding under 6 months: the proportion of infants 0-5 months of age who were exclusively breastfed in the last $24 \mathrm{~h}$.

Continuous breastfeeding at 1 year: Proportion of children 12-15 months of age who are fed breast milk in the last $24 \mathrm{~h}$.

Timely complementary feeding: Proportion of infants 6-8 months of age who were breastfeeding and receiving solid, semi-solid or soft foods.

Bottle feeding: The proportion of infants less than 24 months of age who were receiving any liquid (including breast milk) or semi-solid food from a bottle with nipple/teat including non-human milk and formula in the last 24 hours.

\section{Results}

\section{Socio-Demographic Characteristics}

Present study, included a total of 182 participants. The majority of the mothers, $146(77.0 \%)$ belonged to 21-30 years age group, $13(7.1 \%)$ mothers belonged to less than 20 years age group while remaining $23(12.6 \%)$ were aged more than 30 years. The mean age of the mothers was 23.6 years. Among the respondents, 143 (78.5\%) mothers were Hindus while remaining 39 (21.4\%) belonged to other religions. Furthermore, $11(6.0 \%)$ of the mothers were illiterate, $117(64.2 \%)$ belonged to social class II/III, $153(84.0 \%)$ were housewives, $97(53.2 \%)$ stayed in joint families, 96 (52.7\%) had male children, while 128 (70.3\%) mothers had two or more children (Table 1).

\section{Awareness on EBF and its Advantages}

Table 2 brings out awareness among mothers about EBF and its advantages. It was observed that $166(91.2 \%)$ of the respondents had heard of EBF, but only $98(53.8 \%)$ actually knew that it meant feeding only breast milk for six months. Furthermore, only $44(24.1 \%)$ mothers rightly brought out that initiation of breastfeeding should be within the first hour of delivery. Most of the mothers 126 (69.2\%) felt that complementary feeding should be started around 6 months of age for the babies. The study brought out that $33(18.1 \%)$ mothers were aware that breast milk protects the baby from many diseases, 21 (11.5\%) were aware that breastfeeding creates a bond between mother and baby while 89 (48.9\%) felt that breast milk is best food for babies. Furthermore, $63.7 \%$ mothers also felt that they may not be producing sufficient milk to meet the nutritional needs of the babies. 
Table 1. Socio-Demographic Characters of Study Population ( $n=182)$

\begin{tabular}{|c|c|c|}
\hline Variables & Frequency & Percentage \\
\hline \multicolumn{3}{|l|}{ Age in years } \\
\hline$<20$ & 13 & 7.1 \\
\hline $21-24$ & 77 & 42.3 \\
\hline $25-30$ & 69 & 37.9 \\
\hline$>30$ & 23 & 12.6 \\
\hline \multicolumn{3}{|c|}{ Literacy status of mother } \\
\hline Illiterate & 11 & 6.0 \\
\hline Primary & 51 & 28.0 \\
\hline Secondary & 73 & 40.1 \\
\hline Above Secondary & 47 & 25.8 \\
\hline \multicolumn{3}{|l|}{ Occupation } \\
\hline House wife & 153 & 84.0 \\
\hline Employed & 29 & 15.9 \\
\hline \multicolumn{3}{|l|}{ Socio-economic status } \\
\hline I & 17 & 9.3 \\
\hline II & 39 & 21.4 \\
\hline III & 76 & 41.7 \\
\hline IV & 41 & 22.5 \\
\hline $\mathrm{V}$ & 09 & 4.9 \\
\hline \multicolumn{3}{|l|}{ Type of family } \\
\hline Nuclear & 85 & 46.7 \\
\hline Joint & 97 & 53.2 \\
\hline \multicolumn{3}{|l|}{ Poverty line } \\
\hline APL & 23 & 12.6 \\
\hline BPL & 159 & 87.3 \\
\hline \multicolumn{3}{|l|}{ Religion } \\
\hline Hindu & 143 & 78.5 \\
\hline Muslim/Others & 39 & 21.4 \\
\hline \multicolumn{3}{|c|}{ Gender of infant under survey } \\
\hline Male & 96 & 52.7 \\
\hline Female & 86 & 47.2 \\
\hline \multicolumn{3}{|c|}{ Number of children in the family } \\
\hline Single & 54 & 29.6 \\
\hline Two & 79 & 43.4 \\
\hline$>$ Two & 49 & 26.9 \\
\hline
\end{tabular}


Table 2. Awareness on Exclusive Breastfeeding and its Benefits of ( $n=182)$

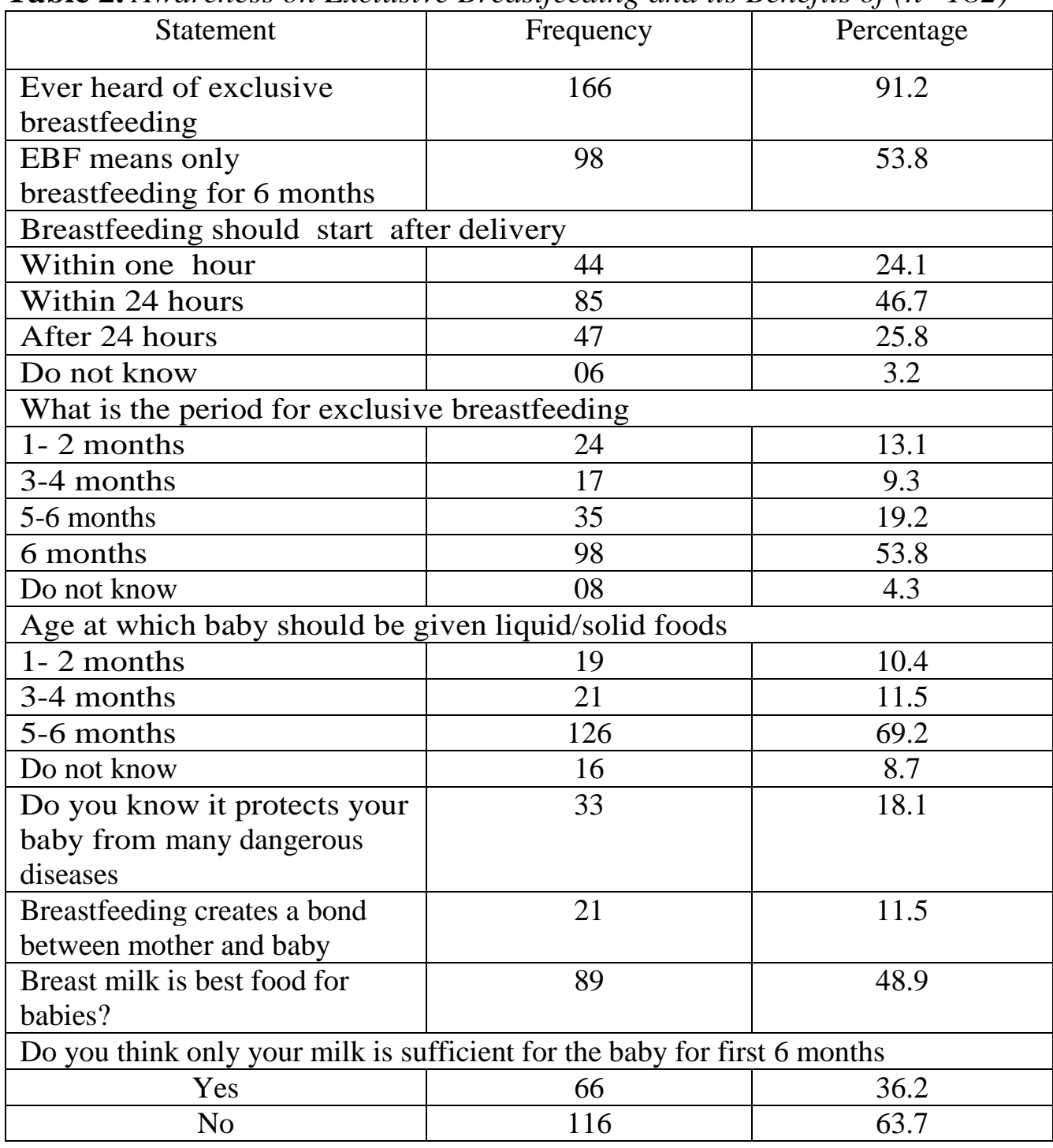

\section{Breastfeeding Practices among Mothers}

Table 3 brings out breastfeeding practices among the respondents. The study brings out that $168(92.3 \%)$ mothers were breastfeeding their babies at the time of interview. It was further observed that, $136(74.7 \%)$ mothers started breastfeeding within the first hour after delivery while $38(20.8 \%)$ started between $1 \mathrm{~h}$ and 24 hours. Majority $161(88.4 \%)$ of the new born babies were given colostrum while $56(30.7 \%)$ were given pre-lacteal feed. Further, $138(75.8 \%)$ mothers practiced breastfeeding on regular basis. Continuous breastfeeding rate at 1 year was found to be $77.3 \%$ while $57.1 \%$ babies were using a feeding bottle. However, timely complementary feeding was provided to only $35.1 \%$ infants. 
Table 3. Breastfeeding Practices among Mothers (182)

\begin{tabular}{|c|c|c|}
\hline Feeding Practices & Frequency & Percentage \\
\hline Currently breastfeeding & 168 & 92.3 \\
\hline Initiation of breastfeeding & \multicolumn{2}{|c|}{} \\
\hline Within one hour & 136 & 74.7 \\
\hline > one h - 24 h & 38 & 20.8 \\
\hline$>$ 24 h & 8 & 4.3 \\
\hline Colostrum given to baby & 161 & 88.4 \\
\hline Timely complementary feeding & 64 & 35.1 \\
\hline Continuous breastfeeding at 1 year & 144 & 79.1 \\
\hline Bottle feeding & 104 & 57.1 \\
\hline Pre-lacteal feed & 56 & 30.7 \\
\hline Frequency of Breastfeeding & \multicolumn{1}{|c|}{} \\
\hline Regularly & 138 & 75.8 \\
\hline On demand & 35 & 19.2 \\
\hline Randomly & 9 & 4.9 \\
\hline
\end{tabular}

\section{Exclusive Breastfeeding}

Present study brings out that $88(48.3 \%)$ mothers practiced EBF while 94 $(51.6 \%)$ mothers did not. The study further brings out that $4.9 \%$ mothers breast fed their babies for duration of less than 90 days, $11.5 \%$ breast fed for 90 to 119 days, $17.0 \%$ breast fed for 120 to 149 days while $18.1 \%$ mothers breast fed their babies for 150 to 179 days (Figure 1).

Figure 1. Prevalence of Exclusive and Non-Exclusive Breastfeeding ( $n=182)$

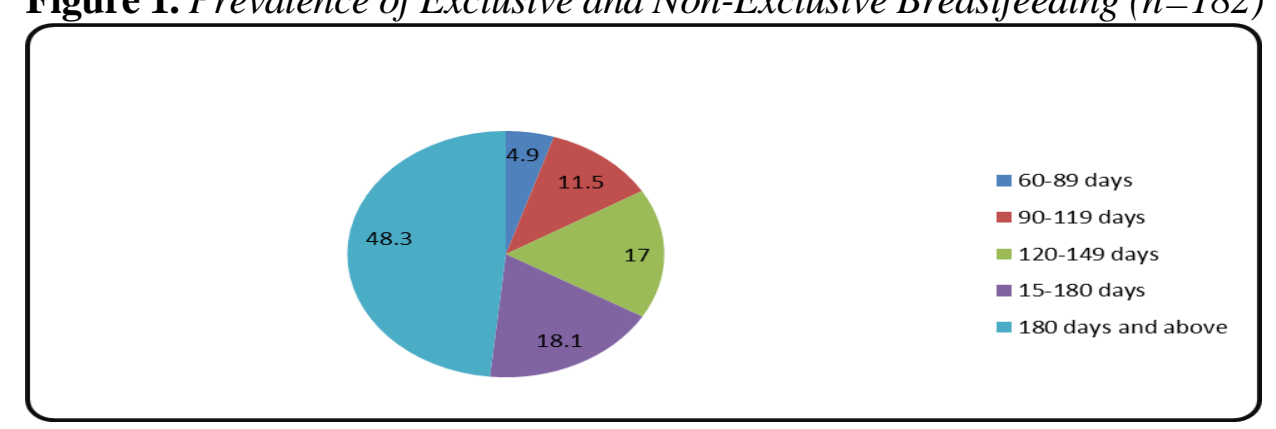

\section{Determinants of Exclusive Breastfeeding}

The present study brings out higher prevalence (58.6\%) of EBF among mothers from higher age group (25 years and above), while mothers in the younger age group (24 years and below) were having lower prevalence $(37.7 \%)$. Further, the EBF practices were found to be high $(60.8 \%)$ among the families which were below poverty line, as compared to those who were above poverty line $(46.5 \%)$. In our study, practice of EBF was found to be almost equal among nuclear as well as joint families i.e., $48.2 \%$ and $48.4 \%$ respectively. Further, the EBF practices were found to be $54.5 \%$ among illiterate mothers while it was $47.9 \%$ among literate mothers. The practice of EBF was found to be relatively 
much higher (54.9\%) among mothers who were house wives/ not working, while only $13.7 \%$ of working mothers practiced EBF.

Among Hindus, 45.4\% and among Muslims, 58.9\% mothers exclusively breast fed their babies. Among 96 male children, $48.9 \%$ while among 86 female children, $47.6 \%$ were provided EBF. The study further brings out that, mothers with a single child practiced EBF in $57.4 \%$ cases as compared to $44.5 \%$ with more than one child. The study reveals $50.8 \%$ prevalence of EBF among mothers who had four or more antenatal visits as compared to $44.2 \%$ among those who had three or less visits. Further, EBF was found to be $30.55 \%$ among mothers who had caesarean section as compared to $52.7 \%$ among those who had normal vaginal delivery.

We tried to establish an association between selected socio-demographic variables and the practice of $\mathrm{EBF}$ and found some of these to be significantly associated and these were-maternal age $(\mathrm{p}<0.004753)$ occupation of the mother $(\mathrm{p}<0.000049)$, gender of the infant $(\mathrm{p}<0.000634)$, number of antenatal visits $(\mathrm{p}<0.01148)$ and type of delivery, i.e. vaginal or caesarean $(\mathrm{p}<0.027847)($ Table 4$)$.

Table 4. Determinants of Exclusive Breastfeeding $n=182$

\begin{tabular}{|c|c|c|c|c|}
\hline Variable & $\begin{array}{c}\mathrm{EBF}(\mathrm{n}=88) \\
(\%)\end{array}$ & $\begin{array}{c}\mathrm{NEBF}(\mathrm{n}=94) \\
(\%)\end{array}$ & $\begin{array}{c}\text { Total }(\mathrm{n}=182) \\
(\%)\end{array}$ & $\chi^{2 / p}$ value \\
\hline \multicolumn{5}{|c|}{ Maternal age in years } \\
\hline$<25$ & $34(37.7)$ & $56(62.2)$ & 90 & 7.9712 \\
\hline$>25$ & 54 (58.6) & $38(41.3)$ & 92 & $\mathrm{p}<0.004753$ \\
\hline \multicolumn{5}{|c|}{ Literacy status of mother } \\
\hline Illiterate & $06(54.5)$ & $05(45.4)$ & 11 & 0.0127 \\
\hline Literate & $82(47.9)$ & $89(52.0)$ & 171 & $p>0.91014$ \\
\hline \multicolumn{5}{|c|}{ Occupation of mother } \\
\hline House wife & $84(54.9)$ & $69(45.0)$ & 153 & 16.4967 \\
\hline Employed & $04(13.7)$ & $25(86.2)$ & 29 & $\mathrm{P}<0.000049$ \\
\hline \multicolumn{5}{|c|}{ Socio-economic status } \\
\hline BPL & $14(60.8)$ & $09(39.1)$ & 23 & 1.652 \\
\hline APL & $74(46.5)$ & $85(53.4)$ & 159 & $\mathrm{p}>0.198693$ \\
\hline \multicolumn{5}{|c|}{ Type of family } \\
\hline Nuclear & $41(48.2)$ & $44(51.7)$ & 85 & 0.5574 \\
\hline Joint & $47(48.5)$ & $50(51.5)$ & 97 & $p>0.453313$ \\
\hline \multicolumn{5}{|c|}{ Gender of infant under survey } \\
\hline Male & $67(69.7)$ & $29(30.2)$ & 96 & 11.6726 \\
\hline Female & $21(24.4)$ & $65(75.5)$ & 86 & $\mathrm{P}<0.000634$ \\
\hline \multicolumn{5}{|c|}{ Number of children in the family } \\
\hline One & $31(57.4)$ & $23(42.5)$ & 54 & 2.5214 \\
\hline$>$ One & $57(44.5)$ & $71(55.4)$ & 128 & $\mathrm{p}>0.112313$ \\
\hline \multicolumn{5}{|c|}{ Antenatal visits } \\
\hline$<$ four & $21(35.0)$ & $39(65.0)$ & 60 & 6.3895 \\
\hline $\begin{array}{l}>\text { four or } \\
\text { more }\end{array}$ & $67(54.9)$ & $55(45.0)$ & 122 & $p>0.01148$ \\
\hline \multicolumn{5}{|c|}{ Type of delivery } \\
\hline Vaginal & $77(52.7)$ & $69(47.2)$ & 146 & 4.8375 \\
\hline Caesarean & $11(30.5)$ & $25(69.4)$ & 36 & $\mathrm{P}<0.027847$ \\
\hline
\end{tabular}




\section{Discussion}

Present study brings out that $92.3 \%$ mothers were breastfeeding their babies at the time of interview, $74.7 \%$ mothers had initiated early breastfeeding, $88.4 \%$ infants were given colostrum, $30.7 \%$ were given pre-lacteal feed, $35.1 \%$ infants were given timely complementary feed and $57.1 \%$ babies were using a feeding bottle. In a similar study in a neighboring district in Karnataka, by Manjunatha Swamy et al. (2015), it was observed that only $17.17 \%$ of mothers intended to exclusively breastfeed their infants for six months while majority of mothers (36.13\%) wanted to continue EBF only for four months. Their study also found that $34.13 \%$ mothers had initiated early breastfeeding while majority $(75.25 \%)$ of the mothers had provided colostrum to their new born babies Manjunatha Swamy et al. (2015). In another study by Bernard Yeboah in Ghana, 74\% of the mothers were found to be breastfeeding their children, more than half of all mothers $(63.4 \%)$ had started early breastfeeding, about $81 \%$ of all mothers had offered colostrum to babies, EBF rate under 6 months was found to be $66 \%$, continuous breastfeeding rate at 1 year was observed to be $77.3 \%, 43.5 \%$ of the infants aged 6-8 months were introduced to complementary feeding and among children less than 24 months, less than half $(30.1 \%)$ were being bottle fed. These findings are similar to our findings (Yeboah-Asiamah Asare 2018).

In our study, less than half of the mothers (48.3\%) practiced exclusive breastfeeding, which is lower than the national average of $54.9 \%$ as well as Karnataka average of $54.2 \%$. Further, the mean duration of EBF among our respondent mothers was 107 days. The study brings out that $51.6 \%$ of the mothers did not complete EBF for 180 days. The study further brought out that $4.9 \%$, mothers breast fed their babies for duration of less than 90 days, $11.5 \%$ mothers breast fed for 90 to 119 days, $17.0 \%$ mothers breast fed for 120 to 149 days while $18.1 \%$ mothers breast fed their babies for 150 to 179 days. In a similar study by Vijayalakshmi et al. (2015) $88.5 \%$ of the mothers were breastfeeders, but only $27 \%$ of the mothers were exclusive breastfeeders and only $36.9 \%$ initiated breastfeeding within an hour (Vijayalakshmi et al. 2015). In another study by Oche and Umar (2008) from in Sokoto, Nigeria, high prevalence of Exclusive breastfeeding was reported, as $78.7 \%$ of the mothers gave only breast milk up to six months after delivery, $71 \%$ of them continued breastfeeding for 19-24 months while majority of the mothers $(76 \%)$ continued breastfeeding even when they felt their child was old enough to be weaned (Oche and Umar 2008).

We tried to identify major determinants of EBF in our study subjects. In our study prevalence of EBF was found to be relatively lower i.e., 37.7\% among younger mothers $(<25$ years) as compared to $58.6 \%$ among the older mothers $(>25$ years) and this difference was also found to be statistically significant $(\mathrm{p}<0.004753)$. Nishimura et al. (2018) in their study from south India also reported increased EBF rates, with increase in maternal age $(\mathrm{OR}=1.04)$ (Nishimura et al. 2018). In a similar study, by Zielinska and Hamulka (2018) in Poland, the researchers also brought out that the highest risk factors for N-EBF were maternal age <20 years (Zielinska and Hamulka 2018). 
Present study brings out that EBF practices were found to be slightly higher $(54.5 \%)$ among illiterate mothers as compared to literate mothers (47.9\%). Similar findings, have also been reported by Akpojene Ogbo et al. (2019) in their studies and brought out that mothers with higher level of education were less likely to exclusively breastfeed their infants (Akpojene Ogbo et al. 2019). However, contrary to our findings, Naik et al. (2019) in their study from Srinagar, India reported significantly higher rates of EBF among babies born to parents with higher education Naik et al. (2019).

In our study prevalence of EBF was found to be higher among housewives (54.9\%) as compared to working mothers (13.7\%) and this was found to be statistically highly significant. In a similar study, Al-Kohji et al. (2012) in Qatar also reported that EBF rates were higher among housewives in comparison with employed mothers, as the unemployed mothers (Al-Kohji et al. 2012). However, contrary to our findings, Basu et al. (2018) reported higher prevalence of EBF among working mothers (50.0\%) as compared to housewives (33.3\%) (Basu et al. 2018).

In our study EBF rate was found to be $60.8 \%$ among the families which were below poverty line (BPL), as compared to $46.5 \%$ among those, who were above poverty line (APL). However, this difference was not found to be statistically significant, ( $p>0.198693)$. In a similar study by Mawa et al. (2019) in Uganda, it was observed that odds ratios for exclusive breastfeeding by household wealth index were 2.38 (1.30-4.33), for the poorest, 2.16 (1.18-3.96) poorer, 1.91 (1.103.48) middle, and 1.41 (0.75-2.64), for richer households (Mawa et al. 2019).

In our study, practice of EBF was found to be almost same among nuclear as well as joint families i.e., $48.2 \%$ and $48.4 \%$ respectively. However, contrary to our findings Gupta et al. (2006) in a study in urban slums of Rishikesh, (Uttar Pradesh) reported higher prevalence of EBF among mothers from Joint families (31.6\%) as compared to mothers from nuclear families $(24.7 \%)$; though this difference was not found to be significant (Gupta et al. 2006).

Gender of infant has been reported to an important determinant of EBF in India. In our study too, $69.7 \%$ male children were given EBF as compared to $24.4 \%$ female children and this difference was also found to be statistically significant ( $\mathrm{p}<0.000634)$. However, Habtewold et al. (2019) in a meta-analysis and Vanderlinden and Van de Putte (2017) in their study in Belgium did not report any significant association between gender of infant and EBF practices (Habtewold et al. 2019, Vanderlinden and Van de Putte (2017).

Present study brought out that, mothers with a single child practiced EBF in $57.4 \%$ cases as compared to $44.5 \%$ with more than one child. Perera et al. (2012) in their study in Sri Lanka brought out that second born babies had a higher exclusive breastfeeding rate $(73.6 \%)$ compared to first born $(70 \%)$ while the EBF rate dropped again after the second baby to $66.6 \%$ (Perera et al. 2012).

Higher numbers of antenatal visits have been found to be associated with the highest odds of EBF. The benefits of breastfeeding should be emphasized during the initial antenatal visit to increase EBF rates among all mothers, though the studies on the association between EBF and number of antenatal visits in India and other countries are not consistent. Present study reveals 50.8\% prevalence of EBF 
among mothers who had four or more antenatal visits as compared to $44.2 \%$ among those who had three or less visits and this difference was also found to be statistically significant ( $p>0.01148$ ). Bhanderi et al. (2019) in their study in Gujarat, also brought out similar findings and observed higher prevalence (52.7\%) of EBF among those who had $>4$ antenatal visits as compared to those who had $<4$ antenatal visits (33.3\%) (Bhanderi et al. 2019).

In majority of studies Caesarean section has been reported to be an important barrier to EBF. In our study too, this trend was observed as EBF was found to be only $30.55 \%$ among mothers who had caesarean section as against $52.7 \%$ among those who had normal vaginal delivery and this difference was also found to be statistically significant $(\mathrm{P}<0.027847)$. In a similar, but prospective cohort study from China, Chen et al. (2018) brought out exclusive breastfeeding rates at 1, 3, and 6 months as $80.2 \%, 67.4 \%$, and $21.5 \%$, respectively and also observed lower rates of EBF among women who had a cesarean delivery than those who had a vaginal delivery $(\mathrm{p}<0.05)$. The authors further observed that Cesarean delivery also shortened the breastfeeding duration (hazard ratio $=1.40,95 \%$ confidence interval) (Chen et al. 2018).

\section{Conclusions}

In our study, EBF practices were found to be suboptimal and below the national as well as Karnataka state average, while these were influenced by multiple socio-demographic variables. The benefits inherent in the practice of EBF cannot be over emphasized, especially in a country like India, where a quarter of global neonatal deaths happen, i.e., nearly 600,000 newborns die within 28 days of their birth every year. Needless to say, that this study brings out an urgent need for health awareness interventions with special focus on the benefits of EBF for both, the infant and the mother. The health education drives should specifically target the new mothers and their family members as the studies indicate a strong influence of mother's parents and her in-laws on breastfeeding practices.

\section{Limitations}

The present study had the limitations which are inherent in all cross sectional studies as these make articulation of temporal association between the study factors and EBF difficult. Further, this was a hospital based study hence data obtained cannot be considered to be the true representative of general population. As the method of data collection in present study was face to face interview, recall bias due to lapse of time and information bias due to personal reasons may not be ruled out. 


\section{Acknowledgements}

The authors are grateful to the participating mothers for their cooperation and time given for the present research, and also to the paramedical staff for their support and help. The Institutional Ethical Committee Approval was obtained before the conduct of study.

\section{References}

Akpojene Ogbo F, Vijaybhai Dhami M, Awosemo AO, Olusanya BO, Olusanya J, Osuagwu UL et al. (2019) Regional prevalence and determinants of exclusive breastfeeding in India. International Breastfeeding Journal 14(20): 1-12.

Al-Kohji S, Said HA, Selim N (2012) Breastfeeding practice and determinants among Arab mothers in Qatar. Saudi Medical Journal 33(4): 436-443.

Andy E (2015) A literature review of the factors that influence breastfeeding: an application of the health believe model. International Journal of Nursing and Health Science 2(3): 28-36.

Bakoula C, Veltsista A, Prezerakou A, Moustaki M, Fretzayas A, Nicolaidou P (2007) Working mothers breastfeed babies more than housewives. Acta Paediatrica 96(4): 510-515.

Basu P, Chakrabartty A, Dasgupta U, Bhattacharyya K, Ali KM, Sarkar AK (2018) Factors influencing exclusive breastfeeding up to six months of age in a rural community of north 24 Parganas, India. Indian Journal of Nutrition 5(1): 181-187.

Behzadifar M, Saki M, Behzadifar M, Mardani M, Yari, F, Ebrahimzadeh F et al. (2019) Prevalence of exclusive breastfeeding practice in the first six months of life and its determinants in Iran: a systematic review and meta-analysis. BMC Pediatrics 19(1): 384.

Bhanderi DJ, Pandya YP, Sharma DB (2019) Barriers to exclusive breastfeeding in rural community of central Gujarat, India. Journal of Family Medicine and Primary Care 8(1): 54-61.

Chen C, Yan Y, Gao X, Xiang S, He Q, Zeng G et al. (2018) Influences of cesarean delivery on breastfeeding practices and duration: a prospective cohort study. Journal of Human Lactation 34(3): 526-534.

Dartmouth-Hitchcock (2020) Risks from supplementing with formula. Retrieved from: https://bit.ly/2R6zG8X.

Edmond KM, Zandoh C, Quigley MA, Amenga-Etego S, Owusu-Agyei S, Kirkwood BR (2006) Delayed breastfeeding initiation increases risk of neonatal mortality. Pediatrics 117(3): e380-e386.

Gupta SK, Gael PK, Kishore S, Singh AB, Semwal J (2006) Social determinants of exclusive breastfeeding practices. Indian Journal of Community Health 18(1): 13-18.

Habtewold TD, Sharew NT, Alemu SM (2019) Evidence on the effect of gender of newborn, antenatal care and postnatal care on breastfeeding practices in Ethiopia: a meta-analysis and meta-regression analysis of observational studies. BMJ Open 9: e023956.

Hamdan A, Tamim H (2012) The relationship between postpartum depression and breastfeeding. The International Journal of Psychiatry in Medicine 43(3): 243-259.

Hayden JA, Chou R, Hogg-Johnson S, Bombardier C (2009) Systematic reviews of low back pain prognosis had variable methods and results: guidance for future prognosis reviews. Journal of Clinical Epidemiology 62(8): 781-796. 
Manjunatha Swamy R, Patil RB, Venugopal (2015) Prevailing breastfeeding practices of infants attending paediatric out-patient department. International Journal of Research in Medical Sciences 3(1): 291-296.

Mawa R, Kambugu Nabasirye C, Mulira J, Nakidde C, Kalyango F, Angulo Alaki Wakida DM et al. (2019) Socio-economic status and exclusive breastfeeding among infants in a Ugandan cross-sectional study. Journal of Food and Nutrition Sciences 7(1): $16-24$.

Ministry of Health and Family Welfare - MHFW (2017) National Family Health Survey 2015-16 (NFHS-4): India fact sheet. Retrieved from: https://bit.ly/2UEsbrX. [Accessed 30 March 2020].

Naik SA, Irshad M, Rasool G, Rafiq WA (2019) The practice of exclusive breastfeeding: its socio-demographic determinants in Kashmir, North India. International Journal of Contemporary Pediatrics 6(2):1-5.

NIH (2017) About breastfeeding and breast milk. Retrieved from: https://www.nichd. nih.gov/health /topics/breastfeeding/condition info. [Accessed 30 March 2020].

Nishimura H, Krupp K, Gowda S, Srinivas V, Arun A, Madhivanan P (2018) Determinants of exclusive breastfeeding in rural South India. International Breastfeeding Journal 13(40): $1-7$.

Oakley LL, Renfrew MJ, Kurinczuk JJ, Quigley MA (2013) Factors associated with breastfeeding in England: an analysis by primary care trust. BMJ Open 3(6): e002765.

Oche MO, Umar AS (2008) Breastfeeding practices of mothers in a rural community of Sokoto, Nigeria. The Nigerian Postgraduate Medical Journal 15(2): 101-104.

Perera PJ, Ranathunga N, Fernando MP, Sampath W, Samaranayake GB (2012) Actual exclusive breastfeeding rates and determinants among a cohort of children living in Gampaha district Sri Lanka: a prospective observational study. International Breastfeeding Journal 7(21): 2-6.

POSHAN (2017) Exclusive breastfeeding in India: trends and data gaps. Retrieved from: https://bit.ly/2UVWzwV. [Accessed 30 March 2020].

Raveendran A, Joseph J, Manjula VD, Sobha A (2020) Prevalence and determinants of exclusive breastfeeding among urban mothers of Central Kerala. International Journal of Community Medicine and Public Health 7(2): 532-536.

Tarrant RC, Younger KM, Sheridan-Pereira M, White MJ, Kearney JM (2010) The prevalence and determinants of breast-feeding initiation and duration in a sample of women in Ireland. Public Health Nutrition 13(6):760-770.

UNICEF (2015) Breastfeeding. Recommendations for optimal breastfeeding. Retrieved from: https: //www.unicef.org/nutrition/index_24824.html. [Accessed 30 March 2020].

UNICEF (2019a) Neonatal mortality. The neonatal period is the most vulnerable time for a child. Retrieved from: https://data.unicef.org/topic/child-survival/neonatal-mortality. [Accessed 30 March 2020].

UNICEF (2019b) Infant and young child feeding. Retrieved from: https://data.unicef. org/topic /nutrition/infant-and-young-child-feeding/. [Accessed 30 March 2020].

Vanderlinden K, Van de Putte B (2017) Pathways of equality through education: impact of gender (in)equality and maternal education on exclusive breastfeeding among natives and migrants in Belgium. Maternal Child Nutrition 13(2): 10.1111/mon.12309.

Victora CG, Bahl R, Barros AJ, França GV, Horton S, Krasevec J et al. (2016) Breastfeeding in the $21^{\text {st }}$ century: epidemiology, mechanisms, and lifelong effect. The Lancet 387(10017): 475-90.

Vijayalakshmi P, Susheela T, Mythili D (2015) Knowledge, attitudes, and breastfeeding practices of postnatal mothers: a cross sectional survey. International Journal of Health Sciences (Qassim) 9(4): 364-374. 
WHO (2008) Indicators for assessing infant and young child feeding practices: conclusions of a consensus meeting held 6-8 November 2007 in Washington D.C., USA. Geneva: World Health Organization.

WHO (2012) Ten steps to successful breastfeeding. Retrieved from: http://www.tensteps. org/ten-facts-breastfeeding.shtml. [Accessed 30 March 2020].

WHO (2013) Counseling for maternal and newborn health care: A handbook for building skills. Breastfeeding. What is so good about breastfeeding? Retrieved from: https:// www.ncbi.nlm.nih. Gov /books/NBK304199/. [Accessed 30 March 2020].

WHO (2017a) 10 facts on breastfeeding. Retrieved from: https://www.who.int/features/ factfiles/breastfeeding/en/. [Accessed 30 March 2020].

WHO (2017b) Tracking progress for breastfeeding policies and programmes. Retrieved from:https://www.who.int/nutrition/publications/infantfeeding/global-bf-scoreca rd2017/en/. [Accessed 30 March 2020].

WHO (2017c) 3 in 5 babies not breastfed in the first hour of life. Breastfeeding within an hour after birth is critical for saving newborn lives. Retrieved from: https://www. who.int/news-room/detail/31-07-2018-3-in-5-babies-not-breastfed-in-the-first-hourof-life. [Accessed 30 March 2020].

WHO (2020a). Breastfeeding. Retrieved from: https://www.who.int/topics/breastfeeding/ en/. [Accessed 30 March 2020].

WHO (2020b) Global targets 2025.To improve maternal, infant and young child nutrition. Retrieved from: https://bit.ly/2UC0gsu. [Accessed 30 March 2020].

WHO and UNICEF (2003) Global strategy for infant and young child feeding. Geneva: World Health Organization.

WikiLectures (2014) Breastfeeding. Retrieved from: https://www.wikilectures.eu/w/Breast _Feeding. [Accessed 30 March 2020].

Yeboah-Asiamah Asare B, Preko JV, Baafi D, Dwumfour-Asare B (2018) Breastfeeding practices and determinants of exclusive breastfeeding in a cross-sectional study at a child welfare clinic in Tema Manhean, Ghana. International Breastfeeding Journal 13(Jun): 12.

Zielinska MA, Hamulka J (2018) Reasons for non-exclusive breast-feeding in the first 6 months. Pediatrics International 60(3): 276-281. 